\title{
So round the spiral again: a reflective participatory research project with children and young people
}

\author{
Niamh O'Brien and Tina Moules* \\ Anglia Ruskin University, UK
}

\begin{abstract}
Historically the voices of children in research have been silent. They are often seen as victims or beneficiaries of research rather than co-researchers or partners. This is beginning to change with rowing awareness that involving children in the design, delivery and evaluation of services can make services more accessible to them and their peers. This article reviews the processes involved $\mathrm{n}$ a research project commissioned by Children's Fund, which investigated the use and non-use of services within a local area. The involvement of children was paramount and resulted in the recruitment $f$ nine young researchers between the ages of 7-13. Various cycles of participatory action research evolved throughout the project and this article focuses specifically on two-recruiting the researcher and training young researchers. We consider the cycles of reflection and action crucial to any participatory project and discuss how lessons were learned to inform further stages of the process. Themes such as challenges, power and participation are discussed throughout.
\end{abstract}

Keywords: Participation; Children; Young people; Research; Involvement; Views; School; Reflection

\section{Introduction}

The role of children and young people in our society today is changing. They are starting to take advantage of a change in thinking which sees them as social actors with the right to participate in decision-making processes (Kirby \& Bryson, 2002; Stafford et al., 2003; Hill et al., 2004). In particular, there is a growing trend for the active involvement of children and young people in the development and delivery of health and social care services underpinned by a range of UK government policies that stress the requirement to listen to and consult with children and young people. The Department of Health specifies the role children and young people can play and commits itself to 'ensuring that the voice of the child is heard and correctly acted upon' in its introduction to the Children's Taskforce (Department of Health, 2001, ifcii). In addition, children's participation is central to a range of UK health legislation such as the Quality Protects Programme (Department of Health, 1999) and is evident in the inspection of children's services, the National Services Framework, Every Child Matters and Youth Matters (Cavet \& Sloper, 2004). As part of the UK government's commitment to tackling those disadvantaged among children and young people, the Children's Fund was launched in November 2000. The voices of children and young people are at the heart of the Children's Fund, with children and young people being involved in the design, operation and evaluation of the programme. The aim of this paper is to discuss issues related to the action research process of developing the project and supporting the children and young people as co-researchers in a participatory evaluative research study funded by a local Children's Fund (the findings will be reported elsewhere). We do this by sharing some of the cycles of reflection and action that occurred during the study. We begin by giving some background to the Children's Fund and presenting a rationale for involving children and young people as coresearchers in the evaluation of services. The methodology used and some of the reflective cycles followed within our study will then be discussed before conclusions for both service provision and the involvement of children and young people in health and social care research are drawn.

\section{Background}

The Children's Fund was launched in the UK in November 2000 in response to the publication of the Social Exclusion Unit's Policy Action Team 12 on Young People (PAT 12) (National Strategy for Neighbourhood Renewal, 2000). The report argued that early identification of children and families at risk of running into severe difficulties could be helped by the implementation of effective service interventions designed to improve children's longer-term 
prospects (National Strategy for Neighbourhood Renewal, 2000). As a result, the Fund is built on three underlying principles namely, prevention, partnership and participation. In particular it aims to set 'children and young people on pathways of participation in society rather than on trajectories of social exclusion' (DfES, 2004, p. 5), and has sought to act as a lever to influence the way services are focused around prevention, partnership working and the involvement of children and young people in their delivery. The programme targets children and young people aged 5-13 at risk of social exclusion and operates across all 150 local authorities in England (Edwards et al., 2006).

To ensure funding was directed in the most effective and appropriate way, the Children's Fund Partnership Board in the local area wanted to understand the reasons why children, young people and their families might not use services. As a result a local University was commissioned to gather information to help Children's Fund Providers understand why services are not being used and ultimately to help them adjust services accordingly. The idea underpinning the project was that knowledge developed would help projects in planning and implementing their services more effectively. To reflect the underlying principle of participation, children and young people actively participated from the start as co-researchers.

\section{Children as co-researchers}

For far too long traditional research has not viewed children and young people as people in their own right; rather their world is investigated from adult perspectives with adults choosing what is investigated. Within this paradigm there is a tendency for researchers, and others, to perceive children as incompetent and incapable of understanding the research process (Christensen \& Prout, 2002) or of being able to give true accounts of their experiences. The image of children as incompetent and in need of protection denies them access to knowledge and to power that in turn increases their vulnerability (Kitzinger, 1990). Thus, the voices of children and young people have been muted within the traditional paradigm of conventional research processes.

More recently, researchers have started to realise that it is possible to learn about children and young people from the 'inside', that is from children and young people themselves:

It is important to involve children and young people in research projects because they have important points of view and hold the answer to a lot of questions. (Research Team of Young People (R.TYP) member, 2005)

The only people who can tell you what it's like to be a child or young person is us so listen to what we have to say. Consulting us about what type of club or group we would like to see in our area rather than telling us what we should be doing is the best way to improve service delivery. (R.TYP member, 2005)

This has led to a different approach as children and young people have become the subjects, rather than the objects, of research thus allowing for their voices to be heard. However, it still means that professional researchers, who make decisions about what is asked and how it is asked, control the whole research process. Moreover, adults control the analysis, interpretation and dissemination of the findings. So a third approach is emerging where children and young people are enabled to participate actively in the research process using participatory research. In this model children and young people work collaboratively with researchers to shape the research agenda.

When children and young people help to shape the research agenda, the way in which they see the world becomes the focus for enquiry rather than relying totally on adult perspectives. Research on children's views can tell us about the types of needs that services supporting children should address. Indeed, Aubrey and Dahl (2005) propose that children's perspectives on the services that they receive can contribute to the development of new knowledge and to the development of more democratic communities. Laws (1998) concluded in her study that it is important for services to recognise the capacity of children to evaluate service provision and give reasoned opinions. They have access to a much larger audience than adults do, and children may be more likely to open up to their peers than to other adults 
(Moules \& Kirwan, 2005). Also, when children produce research reports they attract more publicity and interest in the findings than much adult research (Alderson, 2001).

We've discovered through all this that it is important to involve children and young people in research projects because they have important points of view and hold the answer to a lot of questions. The only people who can tell you what it's like to be a child or young person is us so listen to what we have to say. (R.TYP, 2005, p. 5)

Involving children in all levels of service planning, delivery and evaluation can lead to services that are more equipped to meet their needs.

We've found in our project that if services listen to the views and wishes of children and young people then that service can improve. (R.TYP, 2005, p. 5)

As Hart and Chesson (1998, p. 1602) argue, 'unless children's perceptions ... are known, services cannot respond to their needs and improvements to achieve high quality care cannot be instigated'.

\section{Methodology}

A vital criterion of this project was that children and young people would take an active role in the research process. As Winter and Munn-Giddings propose:

Inquiry must begin with the experiences, perspectives and agendas for inquiry of those whose personal experience is at the centre of the enterprise. (Winter \& MunnGiddings, 2001, p. 57)

The practical outcomes of the study would therefore be grounded in the children's perspectives and interests. A participatory approach to the methodology was adopted with an element of reflective action research cycles where the children were engaged in democratic dialogue as co-researchers. Participatory research is a process of systematic reflective enquiry where researchers and participants actively engage in collaboration to set the research agenda, collect and analyse data, and disseminate the findings so that 'those normally studied become full participants as active agents in the research' (Bernard, 2000, p. 168). The methodology enabled the children and young people to determine the focus of the questions to be asked. It also allowed them to determine the best methods of data collection and to decide where in the community the questions were to be asked.

According to Reason and Bradbury (2001), all participative research can be viewed as action research in that as we participate so we necessarily act. Taking a participatory view of the world requires us to be reflexive and to see inquiry and action as a process of co-creating knowledge. During the two and a half year project there were countless tiny cycles of participatory reflection on action, learning about action and then new informed action (Wadsworth, 1998). Furthermore, both the child and adult researchers were not only researchers but also co-learners as a result of the people they met throughout the research process thus promoting validity as they are all learning through their own lived experience (Wikipedia, 2006).

We have learnt lots of new skills-not only research skills and data collection methods but understanding that everybody can join in even if they have a disability. (R.TYP, 2005, p. 11)

Together the children and researchers absorbed new ways of seeing and thinking, learning about each other and the subject of the study. Together they worked to identify ways of collecting and analysing data and disseminating the findings to making services more accessible to other children, young people and their families. One example of this can be seen in relation to presenting the interim findings in the first year. The young researchers decided they wanted to do this via the use of drama: 
We held a conference were we presented the findings from the first year of our research. Niamh asked us how we would like to do it and we decided we would like to use drama. We thought this would be a really good idea ... All the decisions about the drama were made by the group and this was really good work. I enjoyed working on the drama because we were able to tell adults about the research and express our views about how we felt and also how other children and young people felt about the services delivered to them. (R.TYP member, June 2006)

Ethical approval was gained from the University Ethics Committee and it was highlighted in our application that our work would be underpinned by the fundamental principle of children and young people's right to participation in decisions that affect their lives and, furthermore, by Article 12 of the United Nations Convention on the Rights of the Child (1989) to which the UK is a signatory. The potential vulnerability of children and young people was also addressed in this application; we acknowledged the fine balance between the need for privacy and the need for openness to public scrutiny to assure the personal safety of potentially vulnerable children/young people. The risks to children and young people in this project were deemed to be very low but we did recognise that child protection issues may surface, so a dedicated Child Protection Policy for the project was developed with the support of staff from local Social Services. Furthermore the recruited researcher had an enhanced Criminal Records Bureau Check. Our application also pointed to the fact that children and young people would take part only when they understood what the project was about and when consent was given by them and/or their parents/carers.

Niamh gave us information sheets to take home. One for us and one for our parents so we could talk about it with them and decide if we wanted to join. I decided to join because I thought it was interesting. She also gave us an assent form to sign saying we understood what the project was about and that we could pull out of it at any time. (R.TYP member, March 2005)

As the project progressed, further consent and assent was gained from the young researchers and their parents/carers as needed-such as using photographs for research/publication purposes or attending data collection events.

\section{Cycles of reflection and action}

The cycles of reflection and action occurred naturally as the research progressed. In each of the cases discussed below we can see the four cyclical stages which are common to the action research process namely planning, acting (implementing plans), observing (systematically), reflecting and then re-planning and so round the spiral again (Wadsworth, 1997).

\section{Recruiting the research officer}

The first example relates to the way in which children and young people were involved in recruiting a research officer (Niamh O'Brien) to the project. Involving children and young people in research projects requires that they be active in all aspects of the work. It was important therefore, for the funders and for the researchers that children participated actively in this recruitment process. Many organisations seek to involve children in appointing staff for posts involving children's rights and interests; however the scope of participation can be limited. Very often children are asked simply to respond to a proposal drafted by adults; they are rarely asked to help set the agenda, to specify what they would look for in making an appointment, or draft 'job descriptions'. In this project we aimed to enable much more active participation. We approached a local secondary school, via the Children's Fund, where members of the school council were keen to participate in recruiting the researcher. Though members of the Council only participated in this aspect of the project they were given information about the final findings and recommendations. The first step was to meet with the young people to discuss the project and their role. 
Stage one-planning.

A lunchtime meeting was arranged between members of the school council and two researchers (Tina Moules and another colleague). At this meeting we discussed the background to the project and the importance of involving young people in the recruitment process. At this point, the aim was to involve them in writing the job description and the person specification with a view to discussing their participation in the interview process. We carried out a mind mapping exercise where the young people identified and reflected upon their past experiences (some of them had been involved in recruiting new staff to the school). This reflection enabled the young people to identify the problems and difficulties they had had during their previous experiences. From this came a list of training needs. Together we decided on the need for three workshops. The first would include a brief review of the recruitment process and a more detailed examination of the requirements related to job descriptions and person specifications. The second would be to draft the documents; and the third would be to confirm the documents and plan for the interviews.

Stage two-implementing plans.

The three workshops ran as planned. In the first session the group enacted several role-play situations, reflecting on their observations of each other as they progressed. From this they moved onto drafting and redrafting the job description and person specification in the second and third workshops: 'We talked about the qualities we thought this person should have. I put trustworthy because I thought this was very important when working with young people'. The young people concluded that the successful candidate must:

- Have knowledge of child development.

- Have experience of working with children and/or young people.

- Have an understanding of children and young people.

- Be open-minded and able to listen with a non-patronising approach.

- Be friendly and like being with children and young people.

- Be patient, calm but able to 'control' when necessary.

- Have a sense of humour.

- Be respectful and trusting of children and young people.

- Be trustworthy.

- Be flexible, not too strict.

- Be able to see things from a child's point of view.

- Be determined to make a difference.

All of the above criteria were included in the finalised person specification.

For the researchers, there was always an element of risk here given that the processes and outcomes were in a state of change (Winter, 1989), as the young people reflected, discussed, observed and then acted upon their conclusions. In fact, some of the young people changed the direction of the initial plans by stating that they would like to be involved in short listing and interviewing the candidates. More plans were made, more training needs identified, and so round the spiral again.

\section{Stage three-observing}

A number of young people subsequently took part in short listing the candidates and then two of them sat in on the interviews to observe the candidates. They were given a checklist that had been drawn up by the group and, included the above criteria, and recorded their verdict against each of the three candidates. The interview panel and the young people discussed the performance of each candidate in turn and then had a final discussion, at which stage the decision was agreed with complete consensus. On reflection, one young person commented:

It was strange that the adults thought the same about each candidate as we did, so when it came to making the final selection it was easy because nobody disagreed. 
A period of reflection then ensued as the young people and members of the interview panel evaluated the whole process of participation.

Stage four-re-planning

This stage of the cycle started with the reflection/evaluation as described above. Notes were made on the strengths and weaknesses of the whole process. One young person reported:

I like participating in the interviews because it could prepare me for an interview for when I am older and I also felt the adults listened to me.

The young people gave positive feedback and felt that their participation had resulted in the right person being appointed to the role. They agreed that they had been listened to and that they had influenced the appointment. However, as no more recruitment was planned, the lessons learnt were recorded for future use. It was not until some time later that the replanning took place when, as a direct result of our participatory research project, another group of children and young people were involved in recruiting a participation worker to the Children's Fund. This time the lessons learnt from the first cycles were used to modify the plans and then re-evaluate once again.

\section{Training the young researchers}

When recruiting the young researchers to the project, every attempt was made to ensure they would be as representative as possible of their peers and the area they came from. This was done through contacting all the Children's Fund projects across the two areas we were initially evaluating. Information leaflets in child and young person formats were distributed across the 20 projects detailing the research and why we wanted children and young people to get involved but, nobody came forward so we decided to approach two schools. These were a primary and a secondary school, and they were different to the school used to recruit the research officer (Niamh). Roughly half of these young researchers were from their school council while the remainder were identified by their head teacher. This raises further issues when children are 'hand-picked' as opposed to self-selecting but, given the time we spent on trying to recruit the young researchers in other ways we felt this was the only option open to us.

RTYP was formed because (the local university) wanted some help from children aged 7-14 to find out why they don't use clubs and groups provided for them, especially those funded by the Children's Fund. They thought the best people to help them were children and young people. (R.TYP member, March 2005)

Once the young researchers were recruited their training followed a cyclical reflective process with the initial action being to identify the training needs of the group. In order to record this reflection and action, a timeline was kept by the young researchers which served as a reflective diary for evaluations (Figure 1) (Figures have been removed to protect personal identity).

\section{Stage one-identifying training needs}

On our first training day, the young researchers decided to give their group a name and between them they decided on R.TYP (Research Team of Young People). The name was decided through the use of a suggestion basket which was left on a table throughout the training day. When children and young people had any ideas about what they would like to call the group they placed them in here. We also decided on this first day that we would need to find out where we would access the young people we want to speak to, and this was done through a mapping exercise. Research has shown that using mapping exercises has proven to be effective in groups with children as young as four years old in relation to their perceptions of their environment (Darbyshire et al., 2005). The young researchers decided that holding an event would be the best way to speak to children and young people so we decided to hold a fun day. It was therefore decided that training for interview skills would be required and drawing up questionnaires would be needed for this. 
On our first training day we did a mapping exercise where we used a map of the local area to find out where we would have to go to speak to children and young people.

From this we saw that we would need to talk to them in schools and at fun events.

(R.TYP member, March 2005)

\section{Stage two-providing the training}

The young researchers received training in interview skills carried out through the use of roleplay. We also discussed various research questions and the young researchers were aware of the difference between closed questions, open questions, leading questions, biased questions, probing questions and the ability to check and make sure they understood everything a respondent had said to them. They agreed that during each interview they would verify the answers given by repeating the respondent's answer and adding things like '.. is that right?' or, 'so you think that ...?' They were also instrumental in designing the questions for the fun day event and much discussion took place when completing this task. This training was repeated over a number of sessions and by the time the group was ready to collect data they were confident in how to do this.

We then had to learn how we would ask the children the questions we decided on so Niamh trained us to do this very well. We did interview role-plays where we practiced with each other and Niamh helped us an awful lot when we got stuck. We were given a handout to remind us about what we learnt and what we need to remember in interviews. This is called the interviewing code of conduct. (R.TYP member, June 2006)

Stage three-testing the skills.

Prior to the fun day event the young researchers decided they wanted a trial run. They saw this as beneficial to them in terms of building their confidence to collect data on the day and also as beneficial to the project in terms of gathering further data. In preparation for this they held a 'mini event' at their respective schools where they gathered views and opinions from their peers through the use of small tape recorders and questionnaires (Figure 2) (Figures have been removed to protect personal identity).

We used questionnaires to get the information from the young people. Some recorded the answers on the question sheet while others recorded them on a small tape recorder. (R.TYP member, March 2005)

Stage four-the fun day: using the skills

The fun day took place in October 2004 and as it was Halloween a group decision was made for all researchers to wear fancy dress. Throughout this day, which included face painting, tshirt and bag design and art work, the young researchers gathered data from children and young people via the use of interviews, questionnaires and various creative methods such as a graffiti wall, comments box and a diary room (Figure 3) (Figures have been removed to protect personal identity).

At this event we had T-Shirt and bag design as well as art work. We also had lots of ways to speak to children and young people about services which we had learnt about through our training. We used focus groups, a diary room, interviews and a comments box. (RTYP member, March 2005)

What I found difficult about this was that some children would not speak to me. I solved this problem by saying this is going to be kept private and confidential (R.TYP member, June 2006)

Stage five-reflection.

Following the fun day, the group met and discussed the outcomes. Overall, everyone was very happy with the day. From here it was decided that data collection would happen through other events arranged throughout the county, and all group members were responsible for 
finding out any information they could. From this, data was gathered through various events held by the county council, the police, district councils and others.

One of the bad things was the venue it was too far away for most people to get to so that's why we feel not many came. However we've learnt from this and for our next event we'll have a venue closer to the centre of town so everybody can get to it. (R.TYP member, March 2005)

Stage six-evaluation

Towards the end of phase one, the young researchers carried out an evaluation of the project to assess how well, or otherwise, they felt it was going. We used a 'dartboard' (drawn onto flip chart paper) to evaluate how the young researchers saw the project in terms of meeting their needs. The happier the young researchers were with an aspect of the project, the nearer they placed their sticker to the centre of the 'dartboard'. The exercise showed contentment with the project and resulted in further discussion and positive engagement. During the evaluation, the young researchers assessed various aspects of the project such as the timing of the meetings, training, fun and they also evaluated the research officer. Some of the positive comments included 'being part of fun things', 'dressing up for the fun day', 'adults listening to young people', 'good being with people of different age groups'. One young researcher reported in relation to her learning that: 'When working as a team we can produce some really good work'. Another young researcher reported that he was able to '... talk to a lot of adults without being shy'. Through this exercise we discovered that refresher training was needed, as well as, 'more boys', 'less meetings' and 'more conferences' so their work could be further disseminated and that other ways of collecting data needed to be implemented.

When evaluating the researcher (Niamh), the young researchers were given an individual person outline whereby aspects of the person specification (see above), were detailed. The young researchers were asked to anonymously decide whether they felt the researcher met or did not meet these criteria. During this part of the exercise, Niamh left the room and Tina carried it out. Colour codes were used so that the young researchers could make their decisions: green meant the researcher met the criterion, black meant the young researcher was unsure, and red meant the researcher did not meet the job description criterion. Overall, it was felt this was a very positive evaluation and helped the team to set clear goals for the next phase of the research.

\section{Stage seven-identifying further training and implementing changes.}

Following the evaluation, new methods such as a web-based questionnaire and focus groups were used, alongside the methods used in phase one, to form the basis for data collection in phase two. The young researchers were also given further training in data collection and analysis which resulted in them producing their own research report and disseminating their findings to larger audiences.

When we were nearly finished collecting the opinions and views of the children and young people about why they don't use services, we decided to write our own research report. We decided that because the adults had one we should have one too and ours would be easier to read than theirs. Also we thought it would be good for us to tell other adults about our work in our way. (R.TYP member, June 2006)

... it could help people to see how much work we did. (RTYP member, June 2006)

\section{Discussion}

The children involved as co-researchers in this project formed the steering group, but their involvement did not end there as they were on the receiving end of Children's Fund services outside this project through school and in after school and weekend clubs. Working together 
on this project facilitated in helping the young researchers to view the research question from other perspectives and have an idea as to why problems of attending and maintaining attendance at services exists in the first place. The cycles of reflection and action gave them the opportunity to consider their approach to the research and for us all to learn about each other's views and opinions.

Attempting to access and understand a child's perspective of their own world can present researchers with many challenges. Firstly, for the young co-researchers there is a danger that they will 'over-identify' with the research participants and assume they understand a lot more than they do (Alderson, 2001, p. 140). There is also the danger that they will take replies for granted and mislay their 'enquiring outsider' position (Alderson, 2001, p.140). However, truth is a personal construct, so like anybody conducting research, children are likely to make assumptions, hold onto attitudes and stereotypes, and even take things at face value (Campbell \& Berry, 2001; Kellett et al., 2004). Secondly, with children as research participants there is a dilemma for researchers to know whether or not they are telling the truth or telling an imaginative tale to impress the researcher or even mislead them (Greene \& Hill, 2005), though the same can be suspected of adults. In order for participatory approaches like ours to be successful, researchers need to use appropriate techniques that do not exclude or patronise children. Using the cycles of action and reflection at all stages of the process, albeit in an informal manner, enabled our young co-researchers to take an active role in decisionmaking that in turn helped us to deal with some of the potential power issues at work between adults and children.

Adult-child relationships are normally based on unequal power relations between the generations. Regardless of this, children should be able to expect respect and openness in their dealings with others as adults do (Roche, 2004), and reciprocate it. Seeking a clear understanding of the feelings and understanding children have, is crucial to finding a solution to problems and issues which affect them but research can be hindered by power relations. Rowe (1991, p. 16) defines power as 'the right to have your definition of reality prevail over other people's definition of reality', which neatly describes the imbalance created by adults whose view of the world is most often used to construct understanding and which forms the basis of knowledge (John, 2003). When adults' views of reality frame research about children and young people, they exert power over the young, and the lives of the young are set most firmly in an adult context. This unequal power relation is sustained by a belief that adults have superior knowledge. In the context of participatory research with children and young people though, it is their view of reality that must prevail if the findings of the study are to have validity in terms of the research claims. In addition, it is aspects of childhood that are being explored and thus it is children and young people who have superior knowledge about this. In this instance, adult power over young people is not absolute as the young people re-negotiate adult-imposed boundaries and assert their autonomy by taking the initiative and gaining control (Moules, 2006).

Power, according to Hill et al. (2004) can be viewed either negatively or positively. If viewed from a negative perspective it is about being able to control others or being controlled by them. Power is therefore a zero-sum concept in which we, as researchers, would have more power and the young people would have less. If this view were taken then adults would need to give up power, as power can only be gained by taking it from another as has been suggested in the literature (Johnson, 1996). However, if a positive view of power is taken, an altogether different possibility emerges. Power as a positive concept is about having the ability or capacity to act. Power becomes a variable and here the concept of no winners or losers recedes. According to Martin, "power in research is not simply concentrated in either the researcher or the researched' (1996, p. 89). Rather, it is dynamic and fluid, a moving force. Foucault (1980) proposes that power is not possessed but exercised, that it is productive rather than purely repressive. In research terms, power is exercised in a vertical direction from the top down (researcher over researched) but is also exercised from the bottom up. So there is not a simple hierarchical loading based on socially constructed characteristics (that is, adult over child). It follows then that power derives not only from the position of the adult over the child but also vice versa. Thus, in the research process: 
Power moves between different actors and different social positions, it is produced and negotiated in the social interactions of child to adult, child to child and adult to adult in the local settings of the research. (Christensen, 2004, p. 175)

We conclude from this that, with regard to participatory research with children and young people, it is not necessary to level out the power inequality as Jones (2004) would assert, nor is it necessary to take power away from the adult. It is about changing adult perceptions and also about changing the relationship between the adults in the project and the children and young people.

Taking the positive view of power fits with the approach to research that questions generational order rather than accepts the assumption that adults are superior and have superior knowledge (Mayall, 2000). This approach accepts that in order to understand the lives of children, data must reflect where children say they are now and be based on their experiences rather than on an analysis based on adults' interpretations of the child's needs and experiences. Participatory research with children gives an ideal opportunity to achieve this as it sets out to frame the research from the young people's perspectives. But, to gain a collaborative partnership and achieve a diffusion of power, children and young people need to believe that this is possible. Our experience and that of others (Mandell, 1991), finds that children and young people tend to think and believe that adults have power over them. They generally lack the experience of seeing adults as being fun, participatory and non-judgmental, seeing them more usually as directing and monitoring. This belief is reinforced by the internalisation of assumptions about the general cultural ideas of power and control in crossgenerational relations between adults and children (Foucault, 1977; Alanen \& Mayall, 2003). In fact, the adults around them socially construct the subordinate role that children play. In the lives of children and young people adults tend to take on 'controlling roles' that give rise to preconceived ideas of what being an adult entails.

Choosing to work from a position of power as a positive concept was challenging at times for us, as the children asserted their reflections and influenced the subsequent actions. One way this came through for Niamh was through the evaluation exercise when the young researchers were evaluating her against her person specification, devised by the previous group of young people used to recruit her. During this process the young researchers were deciding whether or not she had 'lived up' to these criteria, which was quite a new experience for both Niamh and the young researchers as in a sense it was a role reversal. They were very aware that their views and opinions had a very important role to play in this process and with Niamh out of the room it meant they could be honest about how they felt. Furthermore, at a data collection event we had a number of staff from the university helping out. Each worked one to one with a young researcher to gather data. At one point, an adult researcher was finding it difficult to encourage children to speak to him via video recorder (permission from parents was received for us to use this method) so one of the youngest researchers on the team took over and spoke to a number of participants using the video recorder. We, as adults, were stunned as to how this young child could assert so much influence when we as researchers were struggling to do so. As can be seen from the quotes above the young researchers did claim a lot of power; they decided how the website would look, for example, and were adamant about using particular colours and layout. At times, this was challenging, as we had to wait until group meetings before decisions were made which meant quite a time delay in getting the website launched. The challenges were made even greater by the fact that we were constrained by the requirements of the contract. Adults decided that the research needed to be carried out, adults funded it and it was adults who had '... the responsibility to exercise professional authority in relation to the project' (McLaughlin, 2005, p. 36).

When involving young service users in service evaluation and research many opportunities and challenges are presented. Few social theorists for example, have measured how children can influence social change, but rather how they are involved as victims or beneficiaries (James \& James, 2004). This shows the limits of the adult mind rather than the ability of children to participate in decision-making (Carnegie Trust, 2004). Participation work raises self-esteem as children and young people are listened to and taken seriously. They see where their opinions count and develop a sense of responsibility (Hannam, 2001; Kirby et al., 
2003; Oldfield \& Fowler, 2004). Hill (1997) says that hearing children's perspectives is just one perception-like adults-but that this is an extremely important perception given that services are supposed to be about furthering children's welfare (Hill, 1997). If we fail to hear young people's views, opinions and suggestions it is possible that they will become unwilling to participate further in the services on offer and thus in their improvement (Curtis et al., 2004).

\section{Conclusion}

This paper has reflected on the cycles of reflection and action in a participatory research project with children and young people. In doing so, it has reviewed how this process of reflection and action supported the participatory nature of the project. Specifically we suggest that rather than attempt to redress the power imbalance that exists between children and adults, it is possible to view power from a positive perspective and therefore acknowledge the potential for power to be variable, a dynamic moving force. It is important to remember in this type of participatory research, that although the findings are extremely important it is also about how the team engages and how issues of power are dealt with (West, 1996). Historically, adults have had control over the decision-making processes about what is asked and how it is asked. In the project discussed here, children and young people worked collaboratively with researchers to shape the research agenda. As a result of addressing such issues, all team members absorbed new ways of seeing and thinking, learning about each other and the subject of the study.

Without children's perspectives there cannot be a complete account as to why services are not being used, therefore involving them as co-researchers has helped us as adult researchers to understand this problem from children's perspectives. Furthermore, this work is reflective of government policies stressing the need to involve children and young people in relation to the development and delivery of health and social care services.

\section{Acknowledgements}

This research was commissioned by Children's Fund Essex. We would like to thank the head teachers and staff at the two schools involved in this project and we would especially like to thank the young researchers: Robert, Derryn, Georgia, Tilly, Danielle, Nicole, Lauren, James and John. Without them, this research would not have been possible.

\section{References}

Alanen, L. \& Mayall, B. (Eds) (2003) Conceptualising child-adult relations (London, Routledge Falmer).

Alderson, P. (2001) Research by children, Social Research Methodology, 4(2), 139-153.

Aubrey, C. \& Dahl, S. (2006) Children's voices: the views of vulnerable children on their service providers and the relevance of services they receive, British Journal of Social Work, 36(1), 21-39.

Bernard, W. T. (2000) Participatory research as emancipatory method: challenges and opportunities, in: D. Burton (Ed) Research training for social scientists (London, Sage Publications).

Campbell, R. \& Berry, H. (2001) Action research toolkit (Edinburgh, Edinburgh Youth Inclusion Partnership).

Carnegie Trust (2004) Is there a limit to young people's participation? Retrieved from: www.carnegietrust.org.uk/files/exec\%20summary.doc (15 December 2005).

Cavat, J. \& Sloper, P. (2004) The participation of children and young people in decisions about UK service development, Child: care, heath and development, 30(6), 613-621.

Christensen, P. \& Prout, A. (2002) Working with ethical symmetry in social research with children, Childhood, 8(4), 477-497.

Christensen, P. H. (2004) Children's participation in ethnographic research: issues of power and representation, Children \& Society, 18(2), 165-176.

Curtis, K., Liabo, K., Roberts, H. \& Barker, M. (2004) Consulted but not heard: a qualitative study of young people's views of their local health service, Health Expectations, 7(2), 149-156. 
Darbyshire, P., MacDougall, C. \& Schiller, W. (2005) Multiple methods in qualitative research with children: more insights or just more? Qualitative Research, 5(4), 417-436.

Department for Education and Skills (DfES) (2004) Developing collaboration in preventative services for children and young people. The National Evaluation of the Children's Fund. First Annual Report 2003 (London, HMSO).

Department of Health (1999) The quality protects programme. Transforming children's services (London, HMSO).

Department of Health (2001) Children's taskforce: an introduction (London, HMSO).

Edwards, A., Barnes, M., Plewis, I. \& Morris, K. (2006) Working to prevent the social exclusion of children and young people. Final lessons from the national evaluation of the children's fund (Birmingham, University of Birmingham \& Institute of Education).

Foucault, M. (1977) Discipline and punish (London, Allen Lane).

Foucault, M. (1980) Power/knowledge: selected interviews and other writings (New York, Pantheon).

Greene, S. \& Hill, M. (2005) Researching children's experience: methods and methodological issues, in: S. Greene \& D. Hogan (Eds) Researching children's experience: approaches and methods (London, Sage), 1-21.

Hannam, D. (2001) A pilot study to evaluate the impact of the student participation aspects of the citizenship order on standards of education in secondary schools. Available online at: http://www.csv.org.uk/csv/hannamreport.pdf (accessed 30 June 2007).

Hart, C. \& Chesson, R. (1998) Children as consumers, British Medical Journal, 316, 1600 1603.

Hill, M. (1997) Participatory research with children, Child and Family Social Work, 2(3), 171183.

Hill, M., Davis, J., Prout, A. \& Tisdall, K. (2004) Moving the participation agenda forward, Children \& Society, 18(2), 77-96.

James, A. \& James, A. L. (2004) Constructing childhood theory, policy, and social practice (Hampshire, Palgrave Macmillan).

John, M. (2003) Children's rights and power. Charging up for a new century (London, Jessica Kingsley).

Johnson, V. (1996) Starting a dialogue on children's participation, PLA Notes 25 (London, IIED), 30-37.

Jones, A. (2004) Involving children and young people as researchers, in: Fraser, S., Lewis, V., Ding, S., Kellet, M. \& Robinson, C. (Eds) Doing research with children and young people (London, Sage), 113-130.

Kellett, M., Forrest, R., Dent, N. \& Ward, S. (2004) 'Just teach us the skills please, we'll do the rest': empowering ten-year-olds as active researchers, Children and Society, 18(5), 329-343.

Kirby, P. \& Bryson, S. (2002) Measuring the magic? Evaluating and researching young people's participation in decision-making (London, Carnegie Young People Initiative).

Kirby, P., Lanyon, C., Cronin, K. \& Sinclair, R. (2003) Building a culture of participation: involving children and young people in policy, service planning, delivery and evaluation (Nottingham, DfES Publications).

Kitzinger, J. (1997) Who are you kidding? Children power and the struggle against sexual abuse, in: A. James \& A. Prout (Eds) Constructing and reconstructing childhood: contemporary issues in the sociological study of childhood (2nd edn) (London, Falmer Press), 165-189.

Laws, S. (1998) Hear me! Consulting with young people on mental health services. (London, The Mental Health Foundation).

Mandell, N. (1991) The least-adult role in studying children, in: F. C. Waksler (Ed) Studying the social worlds of children: sociological readings (London, Falmer Press), 38-59.

Martin, M. (1996) Issues of power in the participatory research process, in: K. De Koning \& M. Martin (Eds) Participatory research in health. Issues and experiences (Johannesburg, NPPHCN), 82-93.

Mayall, B. (2000) Conversations with children. Working with generational issues, in: $P$. Christensen \& A. James (Eds) Research with children: perspectives and practices (London: Falmer Press), 120-135.

McLaughlin, H. (2005) Willing participants? Community Care, 17-23 March, 36-37. 
Moules, T. \& Kirwan, N. (2005) Children's fund Essex: evaluation of the non-use of services in Essex (Chelmsford, Anglia Ruskin University).

Moules, T. (2006) Whose quality is it? Children and young people's participation in monitoring the quality of care in hospital: a participatory research study. Unpublished Ph.D. Thesis, Anglia Ruskin University.

National Strategy for Neighbourhood Renewal (2000) Report of policy action team 12: young people. Available online at: http://www.neighbourhood.gov.uk/publications.asp?did=299 (accessed on 5 January 2007).

Oldfield, C. \& Fowler, C. (2004) Mapping children and young people's participation in England. Research report RR584 (London, Department for Education and Skills).

R.TYP (2005) Research team of young people: year one synopsis (Chelmsford, Anglia Ruskin University).

Reason, P. \& Bradbury, H. (2001) Handbook of action research, participative inquiry and practice (London, Sage).

Roche, J. (2004) Children's rights: participation and dialogue, in: J. Roche, S. Tucker, R. Thomson \& R. Flynn (Eds) Youth in society (2nd edn) (London, Sage), 42-51.

Rowe, D. (1991) Wanting everything. The art of happiness (London, Harper Collins).

Stafford, A., Laybourn, A., Hill, M. \& Walker, M. (2003) 'Having a say': children and young people talk about consultation, Children \& Society, 17(5), 361-373.

United Nations (UN) (1989) Convention on the Rights of the Child, Adopted and Opened for Signature, Ratification and Accession by General Assembly, Resolution 44/25 of 20th November 1989. Available online at: http://www.unher.ch/html/menu3/b/k2crc.htm (accessed 8 November 2006).

Wadsworth, Y. (1997) Everyday evaluation on the run (2nd edn) (Australia, Allen and Unwin).

Wadsworth, Y. (1998) What is participatory action research, Action Research International (online), paper 2. Available online at: www.scu.edu.au/schools/gcm/ar/ari/pywadsworth98.html (accessed 1 July 2007).

West, A. (1996) Young people, participatory research and experiences of leaving care. PLA Notes No. 25 (London, IIED).

Wikipedia (2006) Participatory action research. Available online at: http://en.wikipedia.org/wiki/Participatory action research (accessed 1 July 2007).

Winter, R. (1989) Action research and the nature of social inquiry: professional innovation and educational work (Aldershot, Gower).

Winter, R. \& Munn-Giddings, C. (2001) A handbook for action research in health and social care (London, Routledge). 